\title{
Dexmedetomidine alleviates smoke-induced bronchial and alveolar epithelial cell injury
}

\author{
Jiageng Hong ${ }^{1}$, Qumin Chen ${ }^{1}$, Yanbin Wang ${ }^{1}$, Shaoli Lin ${ }^{1}$ and Guoqiang Su${ }^{2}$ \\ ${ }^{1}$ Department of Anesthesiology, The First Affiliated Hospital of Xiamen University, Xiamen, China \\ ${ }^{2}$ Department III of Gastrointestinal Surgery, the First Affiliated Hospital of Xiamen University, Xiamen, China
}

\begin{abstract}
Dexmedetomidine (Dex) is a selective $\alpha 2$-adrenoceptor agonist and has ability to prevent inflammation and apoptosis in tissues injury. However, whether Dex could alleviate smoke-induced lung injury remains unknown. This study aimed to explore the protective effects of Dex against smokeinduced lung injury. Bronchial and alveolar epithelial cells were treated with cigarette smoke extract (CSE) for $24 \mathrm{~h}$ to simulate cigarette smoke-induced lung injury. Results showed that CSE reduced cell viability and increased levels of pro-inflammatory cytokines TNF- $\alpha$, IL- $1 \beta$ and IL-6, thus activating NF- $\kappa B$ and COX2 expression. CSE also increased ROS generation, whereas lessened MnSOD and catalase generation. Besides, the ratio of apoptotic cells was enhanced upon CSE stimuli, together with disturbance of apoptotic-related proteins including Bcl-2, Bax and caspase-3. However, Dex reduced the damage of CSE to cell viability. The increased activities of TNF- $\alpha$, IL-1 $\beta$ and IL- 6 induced by CSE were partially attenuated by Dex. Dex also recovered the levels of NF- $\kappa B$ and COX2, as well as $\mathrm{mnSOD}$, catalase and ROS. Furthermore, the increase of cell apoptosis together with imbalance of apoptotic proteins induced by CSE was rescued by Dex. Our results demonstrated that Dex alleviated CSE-induced lung injury through inhibition of inflammation, oxidative stress and apoptosis.
\end{abstract}

Key words: Apoptosis — Dexmedetomidine — Inflammation — Lung injury — Smoking

\section{Introduction}

Chronic obstructive pulmonary disease (COPD) is a worldwide health issue and is predicted to be the third major reason of death by 2020 (Rabe et al. 2007). Cigarette smoke, which contains numerous carcinogens, mutagens, and other toxicants, is the major risk factor of COPD and lung cancer (Guan et al. 2013; Song et al. 2017). Different from other stimuli, cigarette smoke is an exceptionally rich source of oxidants, it is a mixture that contains $>10^{15}$ free radicals per puff and $>5,000$ chemicals per inhalation, causing oxidative stress, inflammatory response, DNA damage, cell death, autophagy and cellular senescence, thus leading to serious lung injury (Cantin 2010; Yao and Rahman 2011; Zhang et al. 2011). A large amount of cellular signaling such as Nrf2, $\mathrm{NF}-\kappa \mathrm{B}$ and PI3K are reported to be involved in cigarette

Correspondence to: Guoqiang Su, Zhenhai Road No.55, The First Affiliated Hospital of Xiamen University, Xiamen, Fujian province, China, 361000

E-mail: sgqlab1@163.com smoke-induced lung injury (Nyunoya et al. 2014). Longterm cigarette smoking significantly increases the risk of COPD and lung cancer. Oxidative stress, inflammation and epithelial apoptosis on the bronchia and alveolus are three believed major steps in smoke inhalation lung injury (Maybauer et al. 2009). Therefore, interference with oxidative stress, inflammation and apoptosis in these cells might be a therapeutic approach to alleviate cigarette smoke-induced lung injury.

Nuclear factor kappa-B $(\mathrm{NF}-\kappa \mathrm{B})$ is a significant transcription factor, which plays a key role in the regulation of inflammation (Yan et al. 2018). In most cells, the inactive NF- $\kappa B$ complexes exist predominantly in the cytoplasm and are inhibited by $\mathrm{I} \kappa \mathrm{B}$ proteins. When signaling pathways are activated, the $\mathrm{I} \kappa \mathrm{B}$ proteins are degraded and NF- $\kappa \mathrm{B}$ dimers will enter the nucleus to regulate target gene expression (Hayden and Ghosh 2011). It can be activated by various important pro-inflammatory factors, including tumor necrosis factors (TNF)- $\alpha$, interleukin (IL)-1 $\beta$ and IL- 6 and in turn is essential for transcription and production of these cytokines (DiDonato et al. 2012). 
In mammals, an oxidative stress condition is created as a result of an imbalance between the generation and the detoxification of reactive oxygen species (ROS) (Candas and $\mathrm{Li}$ 2014). The degradation of the oxidation products depends on the antioxidant enzymes including superoxide dismutase (SOD), catalase, which are critical to maintain the redox balance.

Apoptosis is a form of programmed cell death, resulting in the orderly and efficient removal of damaged cells. It can be triggered by extrinsic apoptotic pathway (death receptordependent) and intrinsic apoptotic pathway (mitochondriadependent) (Pistritto et al. 2016). It is reported that many proteins such as Bcl-2 family and P53 exert pro- or antiapoptotic activity in cells, the disruption of which can result in apoptosis. caspase-3, which belongs to caspase family, is the major executor of apoptosis (Wong 2011).

Dexmedetomidine (Dex) is a highly selective a2adrenoceptor agonist with sedative, analgesic and opioidsparing effects (Keating 2015). Increasing studies have indicated that Dex has good effects on inflammation (Xiang et al. 2014; Liang et al. 2017; Yamakita et al. 2017), apoptosis (Akpinar et al. 2016; Chen et al. 2017, 2018; Liang et al. 2017) and oxidative stress (Akpinar et al. 2016; Chen et al. 2018). In recent years, researches on lung injury confirmed the protective effects of Dex against inflammation-, apoptosis- and oxidative-induced lung injury via inhibiting series of cellular signaling pathways including GSK-3/NF- $\kappa \mathrm{B}$ (glycogen synthase kinase-3), PI3K/AKT (phosphatidylinositol 3-kinase/ protein kinase B) and ROS/JNK (reactive oxygen species/cJun N-terminal kinase) (Li et al. 2018; Meng et al. 2018; Zhang et al. 2019). In addition, a randomized and double-blinded study has demonstrated that Dex administration may provide clinically benefits by improving oxygenation and lung mechanics in patients with moderate COPD undergoing lung cancer surgery (Lee et al. 2016).

However, whether Dex could protect against smokeinduced lung injury is unknown. The objective of this work was to explore the effects of Dex on smoke-induced bronchial and alveolar epithelial cell injury.

\section{Materials and Methods}

\section{Cell culture and treatment}

Human alveolar epithelial cell line (A549) was purchased from American Type Culture Collection (ATCC, USA) and maintained in high-glucose DMEM (Gibco, USA) with $10 \%$ FBS (Wisent, Canada), and $1 \%$ antibiotics (Thermo Fisher, USA) in a $5 \% \mathrm{CO}_{2}$ humidified atmosphere at $37^{\circ} \mathrm{C}$.

Human bronchial epithelial (Beas-2B) cells (ATCC) were cultured in 1640 medium (Abcam, UK) with 10\% FBS (Wisent) and 1\% antibiotics (Thermo Fisher Scientific) in an atmosphere of $5 \% \mathrm{CO}_{2}$ at $37^{\circ} \mathrm{C}$.
Before exposure to CSE, cells were pretreated with $0.1 \mathrm{nM}$ or $1 \mathrm{nM}$ Dex (Orion Pharm Ltd, UK) for $2 \mathrm{~h}$.

\section{Cigarette smoke extract (CSE) treatment}

CSE was obtained using a modification of previous reported method (Wang et al. 2019). In brief, two burning cigarettes (CHUNGHWA, China) without filtration were sucked at a steady flow rate $(8 \mathrm{ml} / \mathrm{s})$. The cigarette smoke was bubbled into serum-free medium and then adjusts the $\mathrm{pH}$ of medium to 7.4. Then this $100 \%$ CSE solution was further diluted with serum-free medium to $10 \%$. A549 and Beas-2B cells were exposed to $10 \%$ CSE to simulate smoke-induced lung injury in vitro and control group was prepared by bubbling air into cell culture medium and filtering.

\section{Cell viability}

For the assessment of cell viability, cells on 24 well plate after smoke exposure with or without Dex pretreatment were cultured for $24 \mathrm{~h}$ under normal condition before assay. Cell Counting Kit-8 (CCK-8) was adopted following the manufacturer's instructions. Briefly, cells were incubated with $50 \mu \mathrm{l}$ of CCK- 8 working solution diluted in $0.5 \mathrm{ml}$ of cell culture medium for $2 \mathrm{~h}$ under normal cell culture condition, and then detected with a microplate reader.

\section{Detection of inflammatory factors and oxidative stress levels}

The levels of pro-inflammatory factors TNF- $\alpha$, IL- $1 \beta$ and IL-6 were tested by enzyme-linked immunosorbent assay (ELISA) kit (Abcam Biotechnology, USA) following the manufacturer's instructions.

ROS production was determined by DCFDA (2'-7'-dichlorodihydro-fluorescein diacetate)-ROS Detection Kit (Abcam Biotechnology, USA). In a short word, A549 and Beas-2B cells were harvested by trypsinization and washed with buffer, then stained with $20 \mu \mathrm{M}$ DCFDA in $1 \mathrm{X}$ Buffer for $30 \mathrm{~min}$ at $37^{\circ} \mathrm{C}$. The fluorescence was assessed by microplate reader at Ex/Em: 485/535 $\mathrm{nm}$.

Cellular manganese superoxide dismutase (MnSOD) activity assay and Catalase assay kit (Abcam Biotechnology, USA) were used to determine MnSOD and catalase activities.

\section{Western blot analysis}

RIPA lysis buffer (Beyotime, China) plus a cocktail of serine and cysteine protease inhibitors (Roche, Switzerland) was used for the extraction of proteins in cell lysates. Protein concentration was judged by BCA kit (Beyotime, China) and equal amount of each sample was separated on a $10 \%$ gradient sodium dodecyl sulfate polyacrylamide gel electrophoresis (SDS-PAGE), then transferred to a polyvinylidene 
A

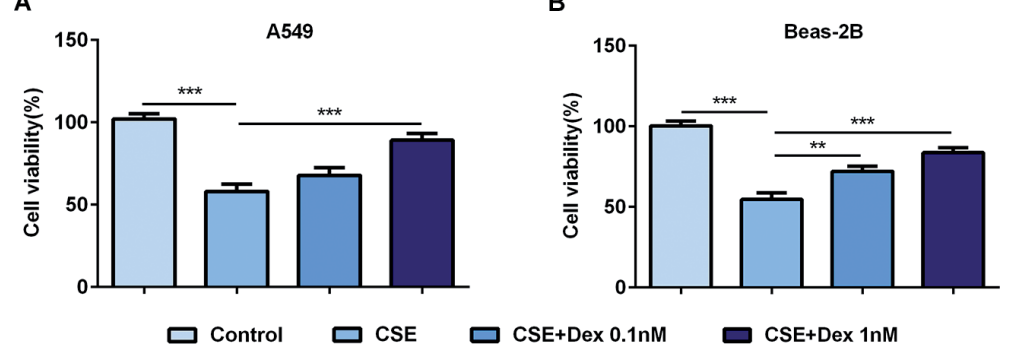

Figure 1. Effect of Dex on cell viability. Cell viability of A549 (A) and Beas-2B (B) cells was quantified by CCK- 8 assay $(n=3)$. Cells were exposed to $10 \%$ CSE with or without 0.1 or $1 \mathrm{nM}$ Dex pretreatment. CSE, cigarette smoke extract; Dex, dexmedetomidine. ${ }^{* *} p<0.01,{ }^{* * *} p<0.001 v s$. CSE treatment. fluoride (PVDF) membrane (Bio-Rad, USA), incubated with $5 \%$ non-fat milk at room temperature for $1 \mathrm{~h}$, and the membranes were treated with primary antibodies against phosphorylated-NF- $\kappa \mathrm{B}, \mathrm{NF}-\kappa \mathrm{B}, \mathrm{COX} 2, \mathrm{Bcl}-2$, Bax, caspase-3, cleaved-caspase-3 and GAPDH (Abcam Biotechnology, UK) at $4^{\circ} \mathrm{C}$ overnight. Next, the membranes were cultivated with horseradish peroxidase (HRP)-conjugated secondary antibodies for $2 \mathrm{~h}$ at room temperature and visualized by the ECL (electrochemiluminescence) system (Amersham, USA).

\section{Flow cytometry}

Cell apoptosis was evaluated by flow cytometry using Annexin V-FITC Kit (Beyotime, China). Briefly, cells were collected and washed with PBS, gently resuspended in Annexin $\mathrm{V}$ binding buffer and incubated with Annexin V-FITC/PI. Flow cytometry was performed using flow cytometer (Becton Dickinson, USA). Data were analyzed by flow cytometry software.

\section{Statistical analysis}

The data processing was according to previous study (Zhang 2016). All experimental data were expressed as mean \pm SD, and GraphPad Prism 6 software (La Jolla, USA) was used in the statistical analyses. $p$ values were calculated using oneway ANOVA analysis; $p<0.05$ was considered statistically significant.

\section{Results}

\section{Effect of Dex on cell viability}

To determine the effect of Dex on cell viability, CCK-8 was used to calculate the ratio of living cells with or without Dex pretreatment before CSE exposure. Cell viability of A549 and Beas-2B was dramatically reduced by CSE, whereas partially rescued by 0.1 or $1 \mathrm{nM} \mathrm{Dex} \mathrm{(Fig.} \mathrm{1),} \mathrm{indicating} \mathrm{the} \mathrm{protective}$ effect of Dex on A549 and Beas-2B cell injury.

\section{Effect of Dex on inflammation}

To examine the effect of Dex on inflammation, we performed ELISA and Western blot analyses. As shown in Figure 2, exposure to CSE significantly increased the activities of pro-inflammatory molecules including TNF- $\alpha$, IL- $1 \beta$ and IL-6, suggesting the occurrence of inflammation induced by CSE in A549 (Fig. 2A) and Beas-2B (Fig. 2B) cells, while
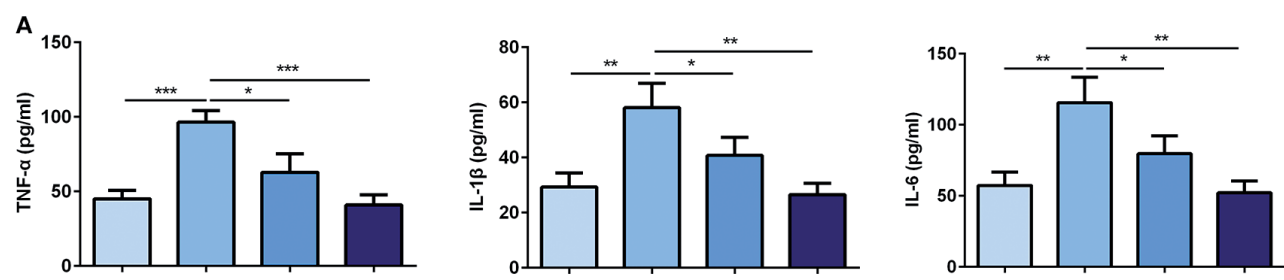

Figure 2. Effect of Dex on inflammatory cytokines levels. A. Alteration of inflam-
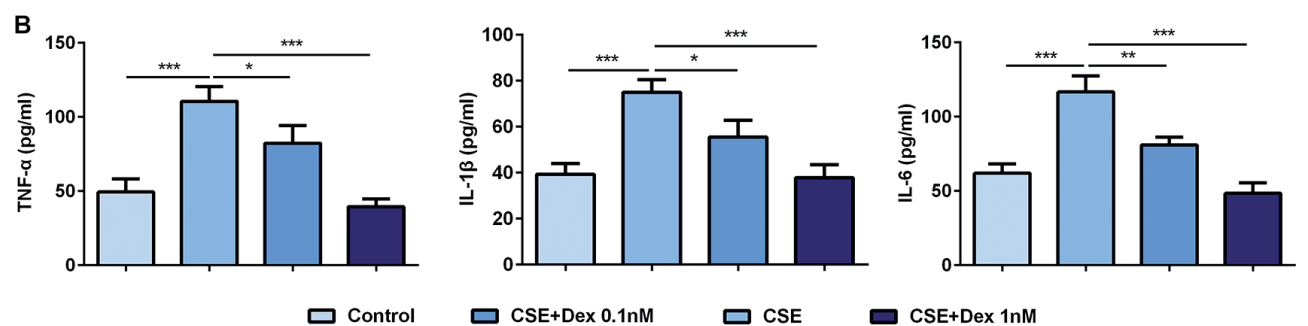
matory cytokines TNF- $\alpha$, IL- $1 \beta$, and IL- 6 levels in A549 cells $(n=3)$. B. Alteration of inflammatory factors TNF- $\alpha$, IL- $1 \beta$, and IL-6 levels in Beas-2B cells $(n=3) .{ }^{*} p<$ $0.05{ }^{* *} p<0.01$ and ${ }^{* * *} p<$ 0.001 vs. CSE treatment. For abbreviations, see Fig. 1. 


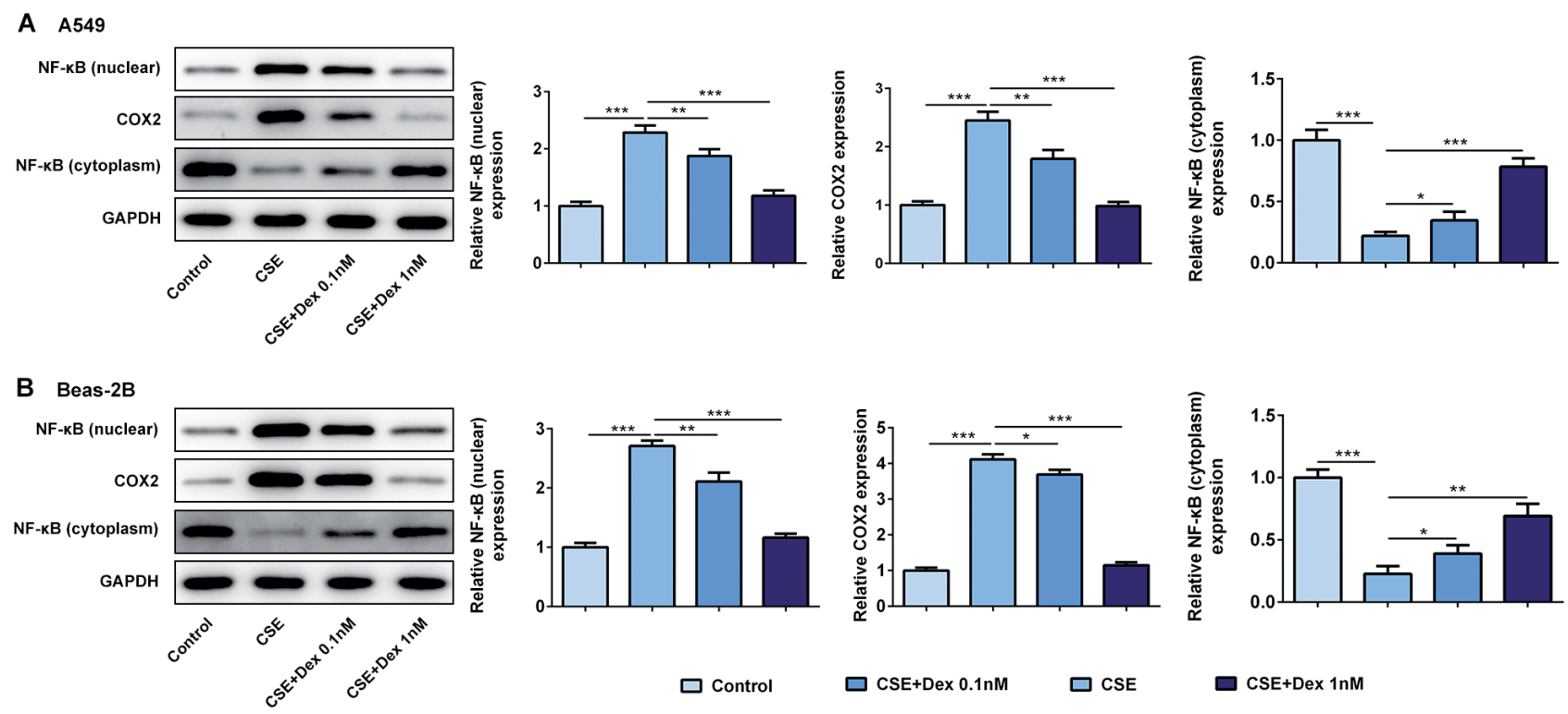

Figure 3. Effect of Dex on expression of inflammatory proteins. A. Representative immunoblot analysis together with relative protein expression of COX2, nuclear and cytoplasmic NF- $\kappa$ B in A549 cells $(n=3)$. B. Representative immunoblot analysis and relative protein expression of COX2, nuclear and cytoplasmic NF- $\kappa$ B in Beas-2B cells $(n=3) .{ }^{*} p<0.05,{ }^{* *} p<0.01$ and ${ }^{* * *} p<0.001 v s$. CSE treatment. For abbreviations, see Fig. 1.

pretreatment with 0.1 or $1 \mathrm{nM}$ Dex reduced CSE-induced inflammation in these two cell lines.

To determine whether increased activities of pro-inflammatory molecules could activate downstream NF- $\kappa B$ pathway, Western blot assay was adopted to evaluate the
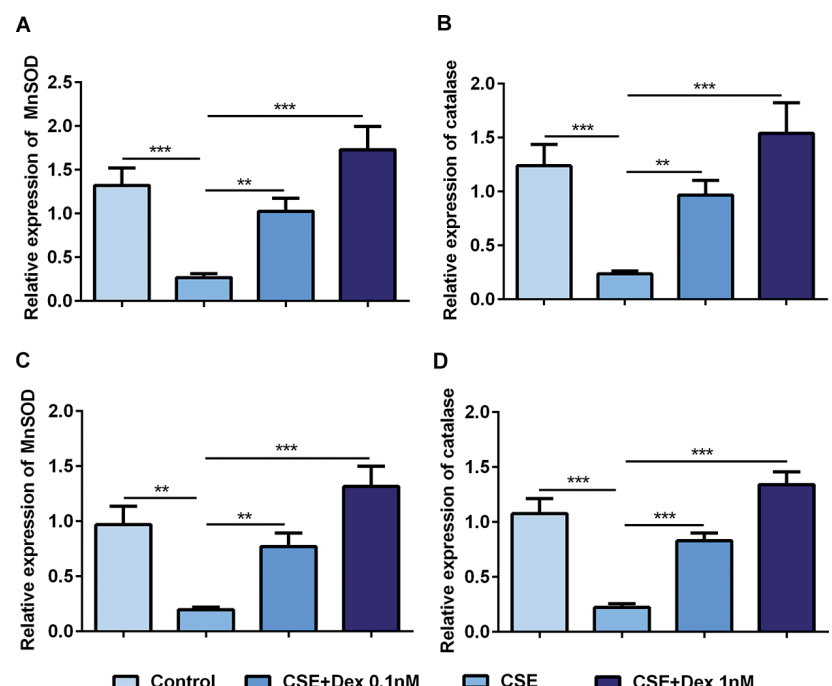

Figure 4. Effect of Dex on MnSOD and catalase. Relative expression of MnSOD and catalase in A549 cells $(n=3)(\mathbf{A}, \mathbf{B})$ and in Beas-2B cell line $(n=3)(\mathbf{C}, \mathbf{D}) .{ }^{* *} p<0.01$ and ${ }^{* * *} p<0.001 v s$. CSE treatment. For abbreviations, see Fig. 1. levels of NF- $\kappa \mathrm{B}$ in the cytoplasm and nucleus, respectively. Expression of nuclear NF- $\kappa \mathrm{B}$, which can initiate transcription of target genes, as well as the inducible cyclooxygenase COX2 was up-regulated in A549 (Fig. 3A) and Beas-2B (Fig. 3B) cells exposed to CSE, indicating the presence of inflammation and activation of NF- $\kappa B$ pathway. However, all these effects were partially reversed by the pretreatment with 0.1 or $1 \mathrm{nM}$ Dex. These results indicated the inhibitory effect of Dex on CSE-caused inflammation.

Effect of Dex on activities of antioxidant enzymes and ROS

To explore the functions of Dex in oxidative stress, the activities of MnSOD, catalase and ROS were detected. Compared with that of control cells, the activities of antioxidant enzymes MnSOD and catalase in CSE-treated A549 (Fig. 4A and B) and Beas-2B (Fig. 4C and D) cells decreased significantly. This effect was blunted by pretreatment with $0.1 \mathrm{nM}$ Dex and further abolished by $1 \mathrm{nM}$ Dex.

To identify whether a functional outcome of the loss in antioxidant activities existed, we checked cellular ROS generation. Treatment with CSE for $24 \mathrm{~h}$ enhanced ROS levels in A549 cells (Fig. 5A and B) and Beas-2B cells (Fig. $5 \mathrm{C}$ and D). Pretreatment with 0.1 or $1 \mathrm{nM}$ Dex inhibited the generation of CSE-increased cellular ROS in A549 and Beas- $2 \mathrm{~B}$ cells. These results suggested that the disturbance of cellular redox induced by CSE can be recovered by Dex. 
A
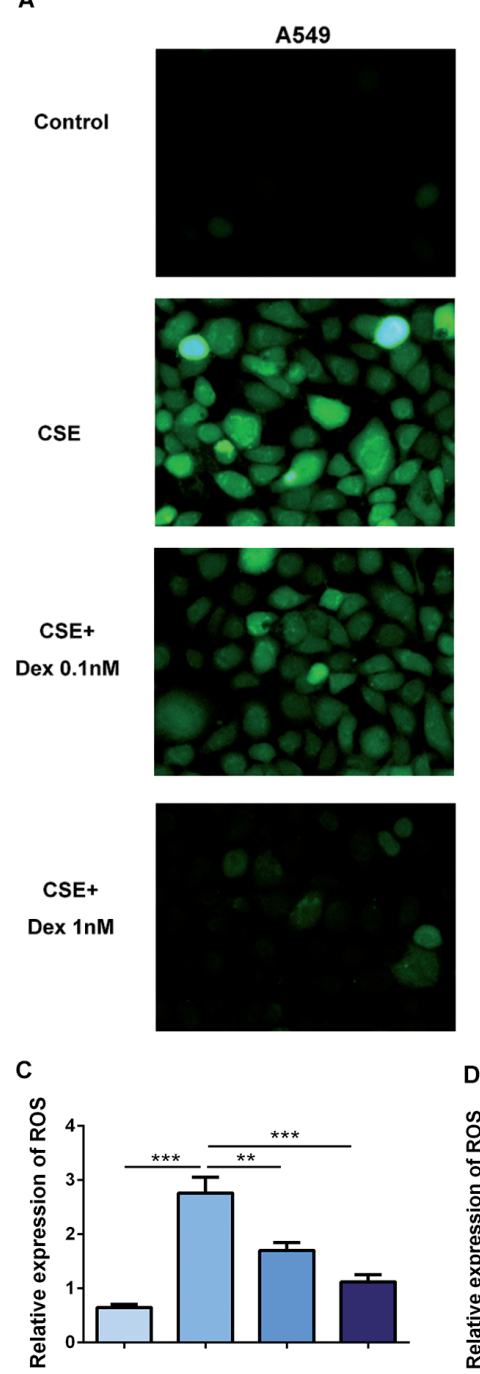

$\square$ Control

$\square$ CSE+Dex $0.1 \mathrm{nM}$

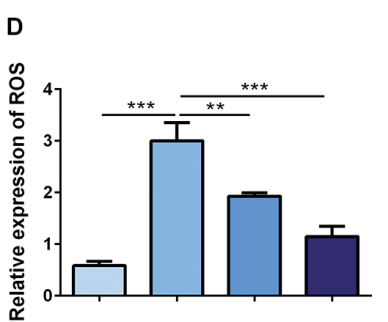

Figure 5. Effect of Dex on ROS generation. ROS generation in A549 (A) and Beas-2B (B) cells were detected by DCFDA-ROS kit and observed under fluorescence microscope (green, A and B; see color Figure in online version of the manuscript); relative expression of ROS was analyzed $(\mathbf{C}, \mathbf{D})(n=3)$. Scale bar $=50 \mu \mathrm{m} .{ }^{\star *} p<0.01$ and ${ }^{\star * *} p<0.001$ vs. CSE treatment. For abbreviations, see Fig. 1.

\section{Effect of Dex on cell apoptosis}

To investigate the role of Dex in cell apoptosis, flow cytometry and Western blot techniques were adopted. CSE exposure resulted in much greater ratio of apoptotic cells in both cell lines. Compare with cells that were treated with CSE alone, both $0.1 \mathrm{nM}$ and $1 \mathrm{nM}$ Dex weakened cell apoptosis (Fig. 6).

Expression of apoptotic protein cleaved-caspase- 3 and pro-apoptotic protein Bax were up-regulated in cells exposed to CSE. The expression of anti-apoptotic proteins Bcl-2 in A549 and Beas-2B cells was down-regulated when detected with Western blot technique, and pretreatment with Dex rescued all these effects (Fig. 7). This result indicated attenuated effect of Dex on CSE-produced apoptosis in lung.
A

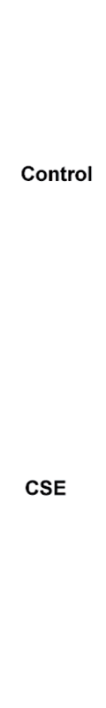

B
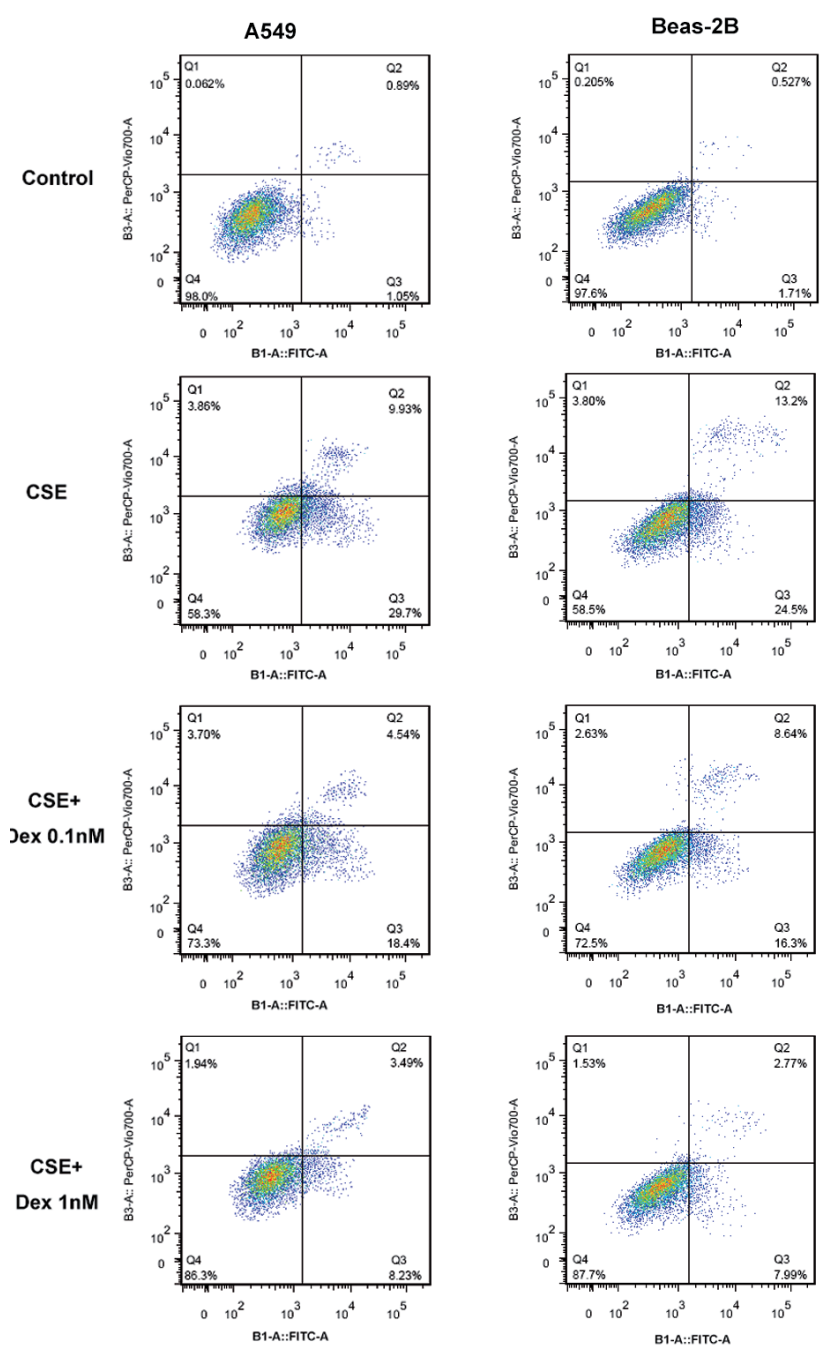

C

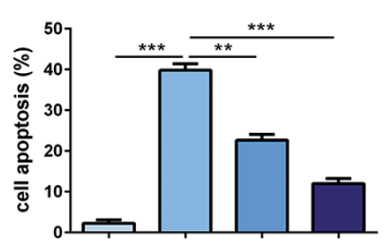

D
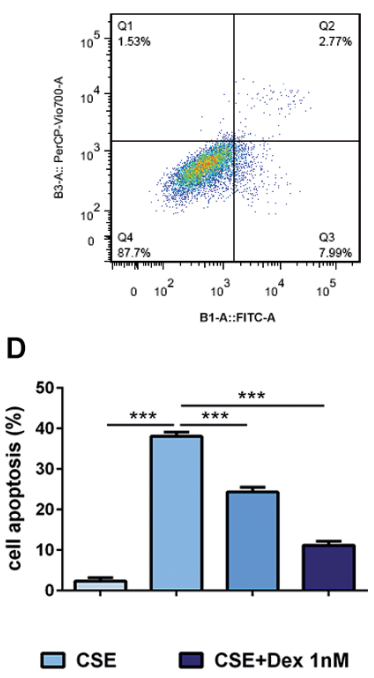

Figure 6. Effect of Dex on the ratio of apoptotic cells. A549 (A) and Beas-2B (B) cell apoptosis was assessed by flow cytometry and the ratios of apoptotic cells in each group were calculated $(\mathbf{C}, \mathbf{D})$. ${ }^{* *} p<0.01$ and ${ }^{* * *} p<0.001$ vs. CSE treatment. 

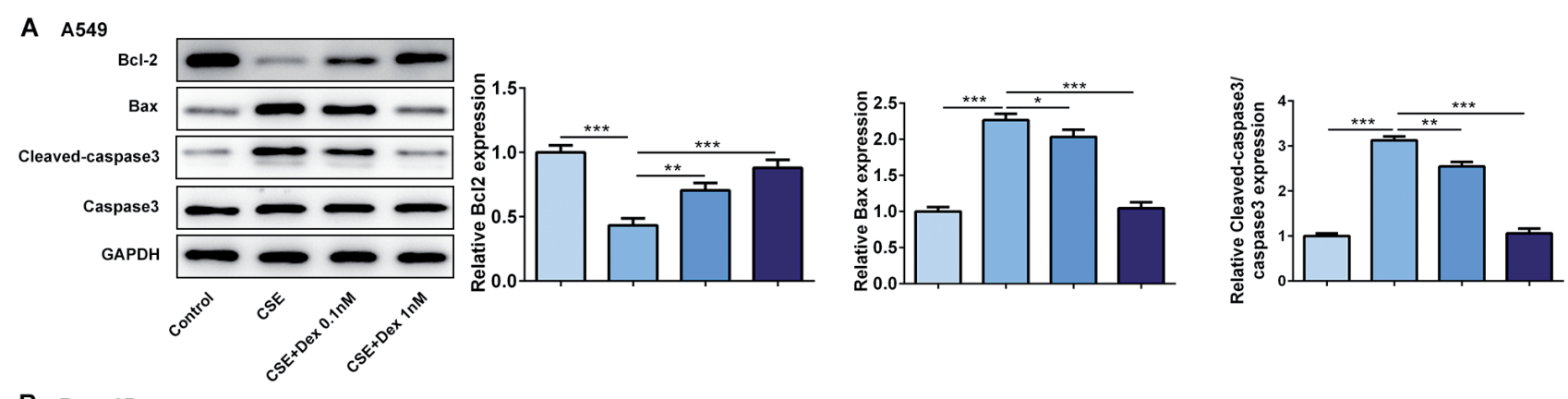

B Beas-2B
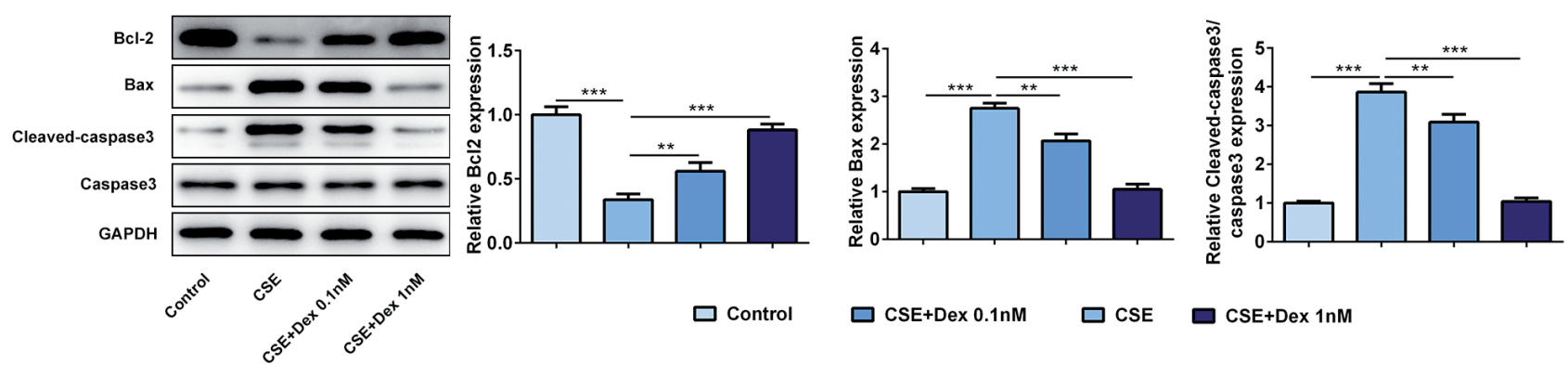

Figure 7. Effect of Dex on expression of apoptosis-related proteins. Representative immunoblot bands together with relative protein expression of Bcl-2, Bax and cleaved-caspase- 3 in A549 (A) and Beas-2B (B) cells, respectively. ${ }^{\star} p<0.05,{ }^{* *} p<0.01$ and ${ }^{* *} p<0.001$ vs. CSE treatment.

\section{Discussion}

The present research, for the first time, shed light on the effect of Dex, a potent $\alpha 2$ adrenergic agonist, on cigarette smoke-induced lung alveolar and bronchial epithelial cell injury. Consistent with previous evidence (Ballweg et al. 2014; Petrusca et al. 2014; Higham et al. 2018; Wang et al. 2019), CSE decreased cell viability and induced excessive generation of pro-inflammatory cytokines TNF- $\alpha$, IL- $1 \beta$ and IL- 6 , thus leading to the activation of NF- $\kappa$ B and COX2. At the same time, CSE increased the level of ROS, whereas decreased antioxidant activities of MnSOD and catalase. What's more, CSE induced cell apoptosis, which is inferred by greater ratio of apoptotic cells, up-regulated expression of cleaved-caspase-3, Bax and reduced expression of antiapoptotic protein $\mathrm{Bcl}-2$.

Dexmedetomidine (Dexdor ${ }^{\circledast}$ ) is widely used in the patients undergoing surgery or under critical care because of its sedative, analgesic, sympatholytic, and hemodynamic effects (Cui et al. 2015). In recent years, it is reported that Dex plays a pivotal role in alleviating inflammation, apoptosis and oxidative stress (Xiang et al. 2014; Akpinar et al. 2016; Chen et al. 2017, 2018; Liang et al. 2017; Yamakita et al. 2017), thus treatment with Dex may be effective in reducing CSE-induced damage to lung cells. In accordance with our speculation, pretreatment with either 0.1 or $1 \mathrm{nM}$ Dex led to an alleviation in exacerbation of inflammation, oxidative stress and apoptosis induced by CSE in lung alveolar and bronchial epithelial cells. Firstly, compared with that of CSE-treated cells, the cell viability was obviously increased by Dex. Secondly, Dex inhibited the activation of NF- $\kappa \mathrm{B}$ and COX 2 caused by CSE. The generation of pro-inflammatory molecules including TNF- $\alpha$, IL- $1 \beta$ and IL- 6 was also reversed by Dex. Thirdly, Dex prevented the occurrence of oxidative stress. Finally, Dex reduced the ratio of apoptotic cells and recovered the balance between anti-apoptotic and pro-apoptotic proteins including $\mathrm{Bcl}-2$, Bax and caspase- 3 .

Previous studies have demonstrated the protective effects of Dex against lung injury (Li et al. 2018; Meng et al. 2018; Zhang et al. 2019), but the specific roles of it in cigarette smoke-induced lung cell injury have been poorly understood. Here, we provided the first evidence that Dex exerted protection against lung alveolar and bronchial epithelial cell injury through inhibition of inflammation, oxidative stress and cell apoptosis. Further in vitro and in vivo studies are needed to investigate the detailed functions and mechanisms of Dex on smoke-induced lung injury.

In conclusion, this study demonstrates that Dex functions as a novel regulator of CSE-induced inflammation, oxidative stress and apoptosis in bronchial and alveolar epithelial cells. Dex can be a valuable therapeutic agent for prevention or treatment of smoke-induced lung injury and COPD. 
Acknowledgements. This work was supported by grants from National Natural Science Foundation of China (NO. 81970462) and Fujian Natural Science Foundation of China (NO. 2015J01548).

Conflict of interest. The authors have declared no conflict of interest.

\section{References}

Akpinar H, Naziroglu M, Ovey IS, Cig B, Akpinar O (2016): The neuroprotective action of dexmedetomidine on apoptosis, calcium entry and oxidative stress in cerebral ischemia-induced rats: Contribution of TRPM2 and TRPV1 channels. Sci. Rep. 6, 37196 https://doi.org/10.1038/srep37196

Ballweg K, Mutze K, Konigshoff M, Eickelberg O, Meiners S (2014): Cigarette smoke extract affects mitochondrial function in alveolar epithelial cells. Am. J. Physiol. Lung Cell. Mol. Physiol. 307, 895-907 https://doi.org/10.1152/ajplung.00180.2014

Candas D, Li JJ (2014): MnSOD in oxidative stress responsepotential regulation via mitochondrial protein influx. Antioxid. Redox. Signal. 20, 1599-1617 https://doi.org/10.1089/ars.2013.5305

Cantin AM (2010): Cellular response to cigarette smoke and oxidants: adapting to survive. Proc. Am. Thorac. Soc. 7, 368-375 https://doi.org/10.1513/pats.201001-014AW

Chen Y, Zhang X, Zhang B, He G, Zhou L, Xie Y (2017): Dexmedetomidine reduces the neuronal apoptosis related to cardiopulmonary bypass by inhibiting activation of the JAK2-STAT3 pathway. Drug Des. Devel. Ther. 11, 2787-2799 https://doi.org/10.2147/DDDT.S140644

Chen Y, Feng X, Hu X, Sha J, Li B, Zhang H, Fan H (2018): Dexmedetomidine ameliorates acute stress-induced kidney injury by attenuating oxidative stress and apoptosis through inhibition of the ROS/JNK signaling pathway. Oxid. Med. Cell. Longev. 2018, 4035310 https://doi.org/10.1155/2018/4035310

Cui J, Zhao H, Yi B, Zeng J, Lu K, Ma D (2015): Dexmedetomidine attenuates bilirubin-induced lung alveolar epithelial cell death in vitro and in vivo. Crit. Care Med. 43, 356-368 https://doi.org/10.1097/CCM.0000000000001035

DiDonato JA, Mercurio F, Karin M (2012): NF-kappaB and the link between inflammation and cancer. Immunol. Rev. 246, 379-400 https://doi.org/10.1111/j.1600-065X.2012.01099.x

Guan SP, Tee W, Ng DS, Chan TK, Peh HY, Ho WE, Cheng C, Mak JC, Wong WS (2013): Andrographolide protects against cigarette smoke-induced oxidative lung injury via augmentation of Nrf2 activity. Br. J. Pharmacol. 168, 1707-1718 https://doi.org/10.1111/bph.12054

Hayden MS, Ghosh S (2011): NF-kappaB in immunobiology. Cell. Res. 21, 223-244 https://doi.org/10.1038/cr.2011.13

Higham A, Bostock D, Booth G, Dungwa JV, Singh D (2018): The effect of electronic cigarette and tobacco smoke exposure on COPD bronchial epithelial cell inflammatory responses. Int. J. Chron. Obstruct. Pulmon. Dis. 13, 989-1000
https://doi.org/10.2147/COPD.S157728

Keating GM (2015): Dexmedetomidine: A review of its use for sedation in the intensive care setting. Drugs 75, 1119-1130 https://doi.org/10.1007/s40265-015-0419-5

Lee SH, Kim N, Lee CY, Ban MG, Oh YJ (2016): Effects of dexmedetomidine on oxygenation and lung mechanics in patients with moderate chronic obstructive pulmonary disease undergoing lung cancer surgery: A randomised double-blinded trial. Eur. J. Anaesthesiol. 33, 275-282 https://doi.org/10.1097/EJA.0000000000000405

Li J, Chen Q, He X, Alam A, Ning J, Yi B, Lu K, Gu J (2018): Dexmedetomidine attenuates lung apoptosis induced by renal ischemia-reperfusion injury through alpha2 AR/PI3K/Akt pathway. J. Transl. Med. 16, 78 https://doi.org/10.1186/s12967-018-1455-1

Liang H, Liu HZ, Wang HB, Zhong JY, Yang CX, Zhang B (2017): Dexmedetomidine protects against cisplatin-induced acute kidney injury in mice through regulating apoptosis and inflammation. Inflamm. Res. 66, 399-411 https://doi.org/10.1007/s00011-017-1023-9

Maybauer MO, Rehberg S, Traber DL, Herndon DN, Maybauer DM (2009). Pathophysiology of acute lung injury in severe burn and smoke inhalation injury. Anaesthesist. 58, 805-812 https://doi.org/10.1007/s00101-009-1560-X

Meng L, Li L, Lu S, Li K, Su Z, Wang Y, Fan X, Li X, Zhao G (2018): The protective effect of dexmedetomidine on LPS-induced acute lung injury through the HMGB1-mediated TLR4/NFkappaB and PI3K/Akt/mTOR pathways. Mol. Immunol. 94, 7-17 https://doi.org/10.1016/j.molimm.2017.12.008

Nyunoya T, Mebratu Y, Contreras A, Delgado M, Chand HS, Tesfaigzi Y (2014): Molecular processes that drive cigarette smoke-induced epithelial cell fate of the lung. Am. J. Respir. Cell. Mol. Biol. 50, 471-482 https://doi.org/10.1165/rcmb.2013-0348TR

Petrusca DN, Van Demark M, Gu Y, Justice MJ, Rogozea A, Hubbard WC, Petrache I (2014): Smoking exposure induces human lung endothelial cell adaptation to apoptotic stress. Am. J. Respir. Cell. Mol. Biol. 50, 513-525 https://doi.org/10.1165/rcmb.2013-0023OC

Pistritto G, Trisciuoglio D, Ceci C, Garufi A, D`Orazi G (2016): Apoptosis as anticancer mechanism: function and dysfunction of its modulators and targeted therapeutic strategies. Aging (Albany NY) 8, 603-619 https://doi.org/10.18632/aging.100934

Rabe KF, Hurd S, Anzueto A, Barnes PJ, Buist SA, Calverley P, Fukuchi Y, Jenkins C, Rodriguez-Roisin R, van Weel C, et al. (2007): Global strategy for the diagnosis, management, and prevention of chronic obstructive pulmonary disease: GOLD executive summary. Am. J. Respir. Crit. Care Med. 176, 532-555 https://doi.org/10.1164/rccm.200703-456SO

Song MA, Benowitz NL, Berman M, Brasky TM, Cummings KM, Hatsukami DK, Marian C, O'Connor R, Rees VW, Woroszylo C, et al. (2017): Cigarette filter ventilation and its relationship to increasing rates of lung adenocarcinoma. J. Natl. Cancer Inst. 109 https://doi.org/10.1093/jnci/djx075 
Wang M, Zhang Y, Xu M, Zhang H, Chen Y, Chung KF, Adcock IM, Li F (2019): Roles of TRPA1 and TRPV1 in cigarette smoke -induced airway epithelial cell injury model. Free Radic. Biol. Med. 134, 229-238

https://doi.org/10.1016/j.freeradbiomed.2019.01.004

Wong RS (2011): Apoptosis in cancer: from pathogenesis to treatment. J. Exp. Clin. Cancer Res. 30, 87 https://doi.org/10.1186/1756-9966-30-87

Xiang H, Hu B, Li Z, Li J (2014): Dexmedetomidine controls systemic cytokine levels through the cholinergic anti-inflammatory pathway. Inflammation $37,1763-1770$ https://doi.org/10.1007/s10753-014-9906-1

Yamakita S, Matsuda M, Yamaguchi Y, Sawa T, Amaya F (2017): Dexmedetomidine prolongs levobupivacaine analgesia via inhibition of inflammation and p38 MAPK phosphorylation in rat dorsal root ganglion. Neuroscience 361, 58-68 https://doi.org/10.1016/j.neuroscience.2017.08.011

Yan C, Deng C, Liu X, Chen Y, Ye J, Cai R, Shen Y, Tang H (2018) TNF-alpha induction of IL-6 in alveolar type II epithelial cells: Contributions of JNK/c-Jun/AP-1 element, C/EBPdelta/C/ EBP binding site and IKK/NF-kappaB p65/kappaB site. Mol. Immunol. 101, 585-596 https://doi.org/10.1016/j.molimm.2018.05.004

Yao H, Rahman I (2011): Current concepts on oxidative/carbonyl stress, inflammation and epigenetics in pathogenesis of chronic obstructive pulmonary disease. Toxicol. Appl. Pharmacol. 254, 72-85 https://doi.org/10.1016/j.taap.2009.10.022

Zhang H, Shih A, Rinna A, Forman HJ (2011): Exacerbation of tobacco smoke mediated apoptosis by resveratrol: an unexpected consequence of its antioxidant action. Int. J. Biochem. Cell. Biol. 43, 1059-1064

https://doi.org/10.1016/j.biocel.2009.12.022

Zhang H, Sha J, Feng X, Hu X, Chen Y, Li B, Fan H (2019): Dexmedetomidine ameliorates LPS induced acute lung injury via GSK-3beta/STAT3-NF-kappaB signaling pathway in rats. Int. Immunopharmacol. 74, 105717 https://doi.org/10.1016/j.intimp.2019.105717

Zhang Z (2016): Univariate description and bivariate statistical inference: the first step delving into data. Ann. Transl. Med. 4, 91 https://doi.org/10.21037/atm.2016.02.11

Received: December 17, 2019

Final version accepted: January 21, 2020 